\title{
sciendo
}

\section{THE GENETIC BASIS OF PIEBALD COAT COLOUR IN HUCUL HORSES IN THE CONTEXT OF WHITE MARKINGS AND CRYPTO-TOBIANO AS A BREEDING PROBLEM IN POLAND*}

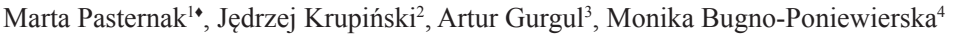 \\ ${ }^{1}$ Department of Sheep and Goat Breeding, National Research Institute of Animal Production, \\ 32-083 Balice n. Kraków, Poland \\ ${ }^{2}$ Department of Horse Breeding, National Research Institute of Animal Production, \\ 32-083 Balice n. Kraków, Poland \\ ${ }^{3}$ Department of Animal Molecular Biology, National Research Institute of Animal Production, \\ 32-083 Balice n. Kraków, Poland \\ ${ }^{4}$ Department of Veterinary, Reproduction and Animal Welfare, University of Agriculture in Kraków, \\ Al. Mickiewicza 24-28, 30-059 Kraków, Poland \\ •Corresponding author: marta.pasternak@izoo.krakow.pl
}

\begin{abstract}
The aim of the study was to analyse the genetic basis of piebald coat colour in Hucul horses and to verify their coat colour in breeding records. Tests were performed with DNA purified from the whole blood samples of 242 Hucul horses with different coat colour patterns. DNA was analysed to identify an inversion in ECA3 (PCR). The results confirmed that the inversion on ECA3 is a direct factor determining piebald (tobiano) colour in the analysed Hucul horses. No inversion was observed in any of the solid coloured horses, but it was present in all the piebald ones. It was also identified in $18 \%$ (11 of 61 ) of the horses from the group of horses qualified in the passport as solid coloured with white markings. In fact, these horses had the tobiano gene that is phenotypically identifiable as crypto-tobiano, which may give the false impression of having white markings and lead to error when describing a horse. This is an important issue, in particular with regard to the breed standard, which eliminates Hucul horses with white markings from breeding.
\end{abstract}

Key words: Hucul horses, piebald, crypto-tobiano, white markings, PCR

In equine breeding, knowledge of coat colour genetics allows for conscious and well-thought out planning of matings as well as proper selection of mating pairs for reproduction (Brooks and Bellone, 2013). Recent years have seen a significant increase in the popularity of piebald horses. They have become highly valued and in

\footnotetext{
*Work financed from statutory activity of the National Research Institute of Animal Production.
} 
demand, but these preferences have been the subject of controversy and discussion in the Hucul horse breeder community. Some concern was caused by the appearance in breeding of more solid coloured horses with white markings, and the transmission of white markings to progeny was largely attributed to piebald parents. According to the breed standard, piebald coat colour is a normal trait, but white markings are a fault which eliminate Hucul horses from breeding. No white markings are allowed in the stallions, whereas the mares may have white markings to a small extent (IZ PIB, 2010; Jansen and Jansen, 2012; PZHK, 2014).

In the case of the tobiano pattern, which corresponds most closely to the pattern of white patches in piebald Hucul horses, the body area covered with patches may vary (Sponenberg and Bellone, 2017). It was assumed that the tobiano pattern is determined by the KIT gene, which was found to be related to similar white patterns in mice and pigs (Stephenson et al., 1994; Nagle et al., 1995; Giuffra et al., 1999) and other white patterns in horses, like sabino or dominant white (Haase et al., 2009; Hauswirth et al., 2013). A comparative analysis of DNA sequences performed by Brooks et al. (2002) showed a substitution (G to C) in intron 13 of the KIT gene in horses with the tobiano pattern, which creates an additional cutting site for the MspI restriction enzyme. The allele with the extra cutting site was designated $K M 1$, while the allele associated with solid coat colour was designated $K M O$. The recognition of the substitution as the cause of tobiano was not completely accurate, because the KMI allele was also found in a few solid coloured horses (Brooks et al., 2002). Ultimately, the direct factor responsible for tobiano was identified by the team of Brooks et al. (2007). FISH analysis showed that in tobiano horses, the long arm (q) of chromosome 3 (ECA3) contains a paracentric inversion whose distal end is located between the KDR and KIT genes (ECA3q21), and proximal end between the $A D H 1 C$ and UNC5C genes (ECA3q13) (Bailey and Brooks, 2010). This inversion was identified in 13 different breeds of tobiano patterned horses. It is also known that tobiano colour is inherited as a dominant trait (Brooks et al., 2007; Bailey and Brooks, 2010).

Depending on the extent, there are three variants of the tobiano pattern: minimal, classic, and maximal. Minimally marked tobianos may have partially white limbs as the only visible evidence of piebaldness, in addition to a small patch of white in the mane or tail, or some other small white spots on the body, which express the tobiano gene (Rees, 2003; APHA, 2007). It happens that a minimally marked tobiano is misclassified as a horse with white markings, which in the case of Hucul horses may preclude them from breeding. Such a mistake may result in a loss of valuable genetic material, which is important to preserve the biodiversity of this native breed. It is therefore necessary to ensure that a horse with white patches (especially on the legs), which has a piebald ancestor in its pedigree, is, in fact, piebald. A horse with the $T O$ (tobiano) allele may transmit it to its progeny, in which the gene may appear as the minimal, maximal, or classic pattern (Stachurska, 2012; Sponenberg and Bellone, 2017).

In 2012, the proportion of piebald horses in the population of Hucul mares and stallions in Poland was estimated to be 22\% (Stachurska et al., 2012), which may result in a similar annual number of piebald progeny. The analysis for 2009-2011 
showed that the proportion of solid coloured foals with white markings, derived from the mating of piebald parents, was $6.3 \%$. However, there is no information if the horses with white markings had been tested for inversion on ECA3. Accordingly, it cannot be ruled out that some of them carried the tobiano gene, which emerged as the crypto-tobiano pattern (Gibała, 2012). The essence of the problem was indicated by Stachurska and Jansen (2015), who provided examples of crypto-tobiano Hucul horses which had been described in passports as solid coloured with white markings.

The aim of the study was to analyse genetic variants associated with piebald coat colour in Hucul horses, to verify their coat colour, and to provide a detailed description of the horses whose coat colour was wrongly determined in their passport.

\section{Material and methods}

\section{Animals and data collection}

The material of the study was blood samples collected from 242 Hucul horses, which were used to purify DNA necessary for molecular analyses. The horses originated from state-owned studs and private breeders and were divided into 3 study groups: I - piebald horses ( $\mathrm{n}=106$, including 61 mares, 16 stallions and 29 geldings) with the pattern typical for minimal or classic tobiano (no maximal tobiano horses were observed in the studied group); II - horses qualified in the passport as solid coloured with white markings ( $\mathrm{n}=61$, including 31 mares, 17 stallions and 13 geldings), having white markings on the limbs and/or head with different expression levels; III - solid coloured horses, which were the control group $(n=75$, including 58 mares, 11 stallions and 6 geldings). Each group was subdivided into 3 subgroups designated: 0 - no piebald parent, 1 - one piebald parent, 2 - two piebald parents. The horses were divided into groups and subgroups based on the description in their passports and on phenotypic description. After coat colour verification carried out through the identification (PCR) of ECA3 inversion, groups were rearranged into new ones.

\section{PCR analysis}

Genomic DNA was purified from blood according to the manufacturer protocol using the Sherlock AX kit (A\&A Biotechnology). Inversion on ECA3 was identified with the primers designed by Brooks et al. (2007): ECA3-F: 5'-TGA TAG ATC AGT GTA GAC GTA GTG TGA CAG AGA C-3'; ECA3xR: 5'-AAC AGC TAC TCC CAC TCT AGC ATA GGT TC-3'; ECA3toR: 5'-TTC ACC ACA GAG TAT CCA ATT ATG TCT TTC ACA TAA TGC-3'. PCR was performed using the QIAGEN Fast Cycling PCR Kit and BioRad thermal cycler. The $20 \mu 1$ reaction mixture per sample contained: $10 \mu \mathrm{l}$ of FastStart Taq DNA Polymerase, $1.5 \mu 1$ of primers $(10 \mu \mathrm{M}), 1 \mu \mathrm{l}$ genomic of DNA $(50 \mathrm{ng} / \mu \mathrm{l})$ and $7.5 \mu \mathrm{l}$ of $\mathrm{ddH}_{2} \mathrm{O}$. The PCR thermal conditions are shown in Table 1. 
Table 1. PCR thermal conditions

\begin{tabular}{lcccc}
\hline \multicolumn{1}{c|}{ Step } & Time & Temp. $\left({ }^{\circ} \mathrm{C}\right)$ & No. of cycles \\
\hline Polymerase activation & $5 \mathrm{~min}$ & 95 & 1 \\
Denaturation & $5 \mathrm{~s}$ & 96 & \\
Annealing & $5 \mathrm{~s}$ & 57 & 35 \\
Elongation & $7 \mathrm{~s}$ & 68 & \\
Final elongation & $1 \mathrm{~min}$ & 72 & 1 \\
\hline
\end{tabular}

To identify inversion on ECA3, PCR products were separated in 3\% agarose gel with ethidium bromide. Genotypes were determined as follows: - / - for recessive homozygote (product size $152 \mathrm{bp}$ ), - / inv for heterozygote (152 and $209 \mathrm{bp}$ ), inv / inv for dominant homozygote (209 bp).

\section{DNA sequencing}

To obtain PCR products for subsequent sequencing and analysis of the genome fragment spanning the site of inversion on ECA3, Primer3web version 4.0.0 program (http://bioinfo.ut.ee/primer3/) was used to design the primer INV-F: 5'- TGT TGT TTT CTT TAC TAA TTG GGT CAT A-3' and, based on the sequences published by Bailey and Brooks (2010), the primers ECA3xR: 5'- AAC AGC TAC TCC CAC TCT AGC ATA GGT TC-3' and ECA3toR: 5'- TTC ACC ACA GAG TAT CCA ATT ATG TCT TTC ACA TAA TGC-3'. PCR was performed separately for the tobiano and solid colour variants. PCR was performed using QIAGEN Fast Cycling PCR Kit and BioRad thermal cycler. The $20 \mu \mathrm{l}$ reaction mixture per sample contained: $10 \mu \mathrm{l}$ of FastStart Taq DNA Polymerase, $1.5 \mu \mathrm{l}$ of primers $(10 \mu \mathrm{M}), 1 \mu \mathrm{l}$ of genomic DNA (40 ng/ $\mu \mathrm{l})$ and $7.5 \mu \mathrm{l}$ of $\mathrm{ddH}_{2} \mathrm{O}$ (Table 2 ).

Table 2. PCR thermal conditions

\begin{tabular}{l|cccc}
\hline \multicolumn{1}{c|}{ Step } & Time & Temp. $\left({ }^{\circ} \mathrm{C}\right)$ & No. of cycles \\
\hline Polymerase activation & $5 \mathrm{~min}$ & 95 & 1 \\
Denaturation & $5 \mathrm{~s}$ & 96 & \\
Annealing & $5 \mathrm{~s}$ & 58 & 35 \\
Elongation & $15 \mathrm{~s}$ & 68 & \\
Final elongation & $1 \mathrm{~min}$ & 72 & 1 \\
\hline
\end{tabular}

PCR products were purified from unused primers and deoxyribonucleotides using Exo-SAP-IT ${ }^{\circledR}$ reagent (USB Corporation). Sequencing was conducted by the chain termination method using fluorescently labelled dideoxynucleotides (ddNTP) from the BigDye ${ }^{\circledR}$ Terminator v3.1 Cycle Sequencing Kit (Applied Biosystems). The sequencing reaction was performed in a Bio-Rad thermal cycler with specific primers that had been used for PCR. To increase reading accuracy and to verify SNP identification, the tested fragment was sequenced from two complementary DNA strands, separately for primer F or R. The $10 \mu \mathrm{l}$ reaction mixture per sample contained: $1 \mu \mathrm{l}$ 
of BigDye ${ }^{\circledR}$ Terminator v3.1 Ready Reaction Mix, $1 \mu$ l of BigDye ${ }^{\circledR}$ Sequencing Buffer, $1 \mu \mathrm{l}$ of primer $(5 \mu \mathrm{M})\left(\mathrm{F}\right.$ or R), $1 \mu \mathrm{l}$ of PCR product and $6 \mu \mathrm{l}$ of $\mathrm{ddH}_{2} \mathrm{O}$ (Table 3 ).

Table 3. Thermal conditions used for sequencing

\begin{tabular}{lc|c|c}
\hline \multicolumn{1}{c|}{ Step } & Time & Temp. $\left({ }^{\circ} \mathrm{C}\right)$ & No. of cycles \\
\hline Initial denaturation & $1 \mathrm{~min}$ & 96 & 1 \\
Denaturation & $10 \mathrm{~s}$ & 96 & 25 \\
Annealing & $5 \mathrm{~s}$ & 50 & \\
Elongation & $4 \mathrm{~min}$ & 60 & - \\
Termination & $\infty$ & 4 & \\
\hline
\end{tabular}

The sequencing products were purified from unused ddNTP and from salts using the BigDye XTerminator ${ }^{\circledR}$ Purification Kit (Applied Biosystems). The sequencing products were electrophoresed on a 16-capillary 3130xl Genetic Analyzer (Applied Biosystems).

\section{Results}

The genotypes determined according to the method by Brooks et al. (2007) are presented in Figure 1. The chromatogram in Figure 2 shows the genome sequence fragment in a solid-coloured horse and in a tobiano patterned horse.

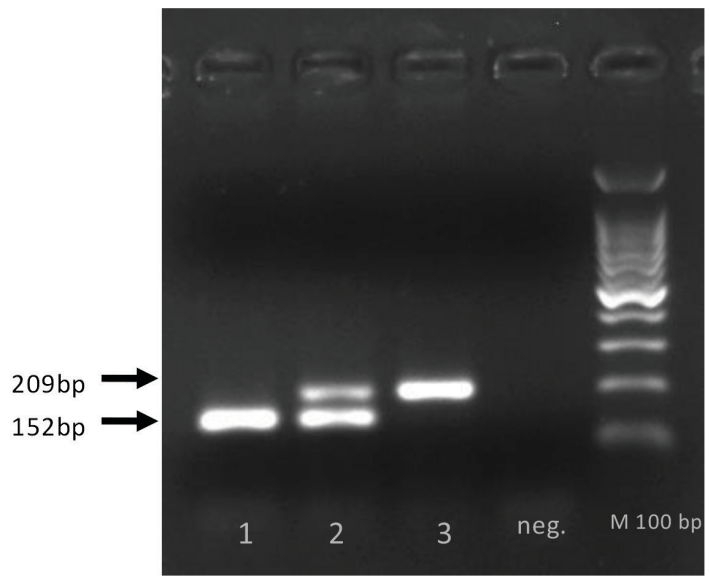

Figure 1. Banding patterns for different genotypes, from the left: 1 - recessive homozygote (-/ -), 2 - heterozygote (- / inv), 3 - dominant homozygote (inv / inv)

The identification of ECA3 inversion demonstrated that the coat colour of 11 horses described as solid coloured with white markings was misclassified. Some pedigree inaccuracies were also found for two horses whose genotype was not consistent with the parents' coat colour described in the passport. Using these results, 
and to ensure that the calculations were correct, the groups were re-divided -11 horses from the group of solid coloured with white markings, which had the inversion on ECA3, were moved to the group of tobiano horses, and next the group of tobiano horses was revised into subgroups based on the correct coat colour of the parents. The distribution of genotypes for ECA3 inversion according to the coat colour classification made on the basis of passport description is presented in Table 4, while the distribution of genotypes following PCR verification as well as the frequency of genotypes $\left(\mathrm{P}_{\mathrm{G}}\right)$ for ECA3 inversion are shown in Table 5.

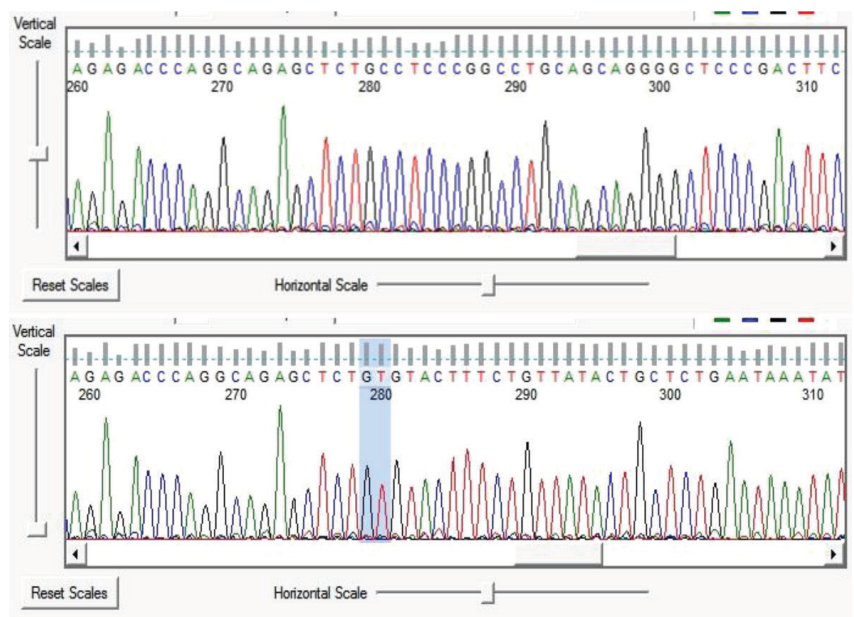

Figure 2. Chromatogram of the genome sequence fragment in a horse without inversion (top) and in a horse with ECA3 inversion (bottom). Darker background indicates the break-point beyond which there is a fragment of the inverted genome sequence of a tobiano horse

Table 4. Genotype distribution for ECA3 inversion in different test groups according to the coat colour classification described in the passport

\begin{tabular}{|c|c|c|c|c|c|c|c|c|c|c|}
\hline \multirow{2}{*}{$\begin{array}{c}\text { Subgroup } \\
\text { (no. of piebald } \\
\text { parents) }\end{array}$} & \multirow{2}{*}{$\begin{array}{c}\begin{array}{c}\text { Coat } \\
\text { colour }\end{array} \\
\text { genotype }\end{array}$} & \multicolumn{3}{|c|}{ Piebald } & \multicolumn{3}{|c|}{$\begin{array}{l}\text { Solid coloured with } \\
\text { white markings }\end{array}$} & \multicolumn{3}{|c|}{ Solid coloured } \\
\hline & & $-1-$ & $-/$ inv & $i n v / i n v$ & $-/-$ & $-/$ inv & inv / inv & $-1-$ & $-/ i n v$ & inv / inv \\
\hline 0 & & 0 & $1^{*}$ & 0 & 38 & $1^{*}$ & 0 & 58 & 0 & 0 \\
\hline 1 & & 0 & 94 & $1^{*}$ & 11 & $9 *$ & 0 & 17 & 0 & 0 \\
\hline 2 & & 0 & 6 & 4 & 1 & $1 *$ & 0 & 0 & 0 & 0 \\
\hline & $\Sigma$ & 0 & 101 & 5 & 50 & 11 & 0 & 75 & 0 & 0 \\
\hline
\end{tabular}

* Asterisk indicates horses with erroneous coat colour description in the passport.

The inversion in ECA3 was identified in all of the examined piebald horses (Table 5). The analysis showed that the only horse from subgroup 0 , which was initially included in this group due to the passport description, had the genotype - / inv (Table 4). This means that it must have inherited the inversion and tobiano pattern from one of the parents. Further tests showed the presence of a heterozygous inversion in the horse's dam, which was described in the passport as solid coloured with white 
markings and having the crypto-tobiano pattern. Therefore, after the verification, the horse was moved from subgroup 0 to subgroup 1 (Table 5). In the subgroup of horses having one piebald parent, one horse was identified to be homozygous inv / inv (Table 4), which also proved the breeding records wrong, because homozygous inversion cannot occur in offspring which have only one tobiano parent (in this case, the sire). Pedigree analysis showed that the dam of this horse, qualified as solid coloured with white markings, was derived from a piebald sire, and the horse studied in the present experiment was not the only piebald offspring of this dam, obtained from the mating with a solid coloured stallion. In fact, this mare must have been piebald and had the crypto-tobiano pattern, which was confused with white markings. The examined horse was moved to subgroup 2 (Table 5).

Table 5. Genotype distribution and frequency $\left(\mathrm{P}_{\mathrm{G}}\right)$ for ECA3 inversion in different test groups after PCR verification of coat colour

\begin{tabular}{|c|c|c|c|c|c|c|c|c|c|c|}
\hline \multirow{2}{*}{$\begin{array}{c}\text { Subgroup } \\
\text { (no. of tobiano } \\
\text { parents) }\end{array}$} & \multirow{2}{*}{\begin{tabular}{|c|} 
Coat colour \\
genotype
\end{tabular}} & \multicolumn{3}{|c|}{ Piebald (tobiano) } & \multicolumn{3}{|c|}{$\begin{array}{l}\text { Solid coloured with } \\
\text { white markings }\end{array}$} & \multicolumn{3}{|c|}{ Solid coloured } \\
\hline & & $-1-$ & $-/ i n v$ & inv / inv & $-1-$ & $-/ i n v$ & inv / inv & $-1-$ & - / inv & inv / inv \\
\hline 0 & & $\begin{array}{c}0 \\
(0.00)\end{array}$ & $\begin{array}{c}0 \\
(0.00)\end{array}$ & $\begin{array}{c}0 \\
(0.00)\end{array}$ & $\begin{array}{c}38 \\
(1.00)\end{array}$ & $\begin{array}{c}0 \\
(0.00)\end{array}$ & $\begin{array}{c}0 \\
(0.00)\end{array}$ & $\begin{array}{c}58 \\
(1.00)\end{array}$ & $\begin{array}{c}0 \\
(0.00)\end{array}$ & $\begin{array}{c}0 \\
(0.00)\end{array}$ \\
\hline 1 & $\left(\mathrm{P}_{\mathrm{G}}\right)$ & $\begin{array}{c}0 \\
(0.00)\end{array}$ & $\begin{array}{c}105 \\
(1.00)\end{array}$ & $\begin{array}{c}0 \\
(0.00)\end{array}$ & $\begin{array}{c}11 \\
(1.00)\end{array}$ & $\begin{array}{c}0 \\
(0.00)\end{array}$ & $\begin{array}{c}0 \\
(0.00)\end{array}$ & $\begin{array}{c}17 \\
(1.00)\end{array}$ & $\begin{array}{c}0 \\
(0.00)\end{array}$ & $\begin{array}{c}0 \\
(0.00)\end{array}$ \\
\hline 2 & & $\begin{array}{c}0 \\
(0.00)\end{array}$ & $\begin{array}{c}7 \\
(0.58)\end{array}$ & $\begin{array}{c}5 \\
(0.42)\end{array}$ & $\begin{array}{c}1 \\
(1.00)\end{array}$ & $\begin{array}{c}0 \\
(0.00)\end{array}$ & $\begin{array}{c}0 \\
(0.00)\end{array}$ & $\begin{array}{c}0 \\
(0.00)\end{array}$ & $\begin{array}{c}0 \\
(0.00)\end{array}$ & $\begin{array}{c}0 \\
(0.00)\end{array}$ \\
\hline & $\Sigma$ & 0 & 112 & 5 & 50 & 0 & 0 & 75 & 0 & 0 \\
\hline & $P_{G}$ in group & $(0.00)$ & $(0.96)$ & $(0.04)$ & $(1.00)$ & $(0.00)$ & $(0.00)$ & $(1.00)$ & $(0.00)$ & $(0.00)$ \\
\hline
\end{tabular}

The most significant results were obtained in the group of solid coloured horses with white markings. Based on the passport description of coat colour, it was assumed that regardless of the subgroup, the inversion would not occur in any of the horses, but in fact 11 horses qualified as solid coloured with white markings had the inversion (Table 4), which means the coat colour in their passports was misdescribed. In reality, each of these horses had a heterozygous tobiano gene - / inv (Figure 3), which showed up as the crypto-tobiano pattern (Figure 4). These horses were moved to the first group (piebald horses), as a result of which the overall genotype frequency in the group of solid coloured horses with white markings, after the revision, was $\mathrm{P}_{\mathrm{G}}=1$ for recessive homozygotes (Table 5).

In the case of the horse from the subgroup of horses having no piebald parents (subgroup 0), which was found to carry heterozygous inversion (Table 4), the coat colour was misdescribed not only for this horse but also for its parents. This horse must have inherited the tobiano pattern from one of the parents, which was confirmed by a subsequent DNA test. It showed an inversion in the dam of the analysed horse, and the phenotypic analysis showed the minimal tobiano pattern in both, which were misdescribed in the passport as solid coloured with white markings. In the control 
group, which included solid coloured horses, there were no horses with ECA3 inversion, irrespective of the number of piebald parents in their pedigree. Genotype frequency was $\mathrm{P}_{\mathrm{G}}=1$ for recessive homozygotes (Table 5).

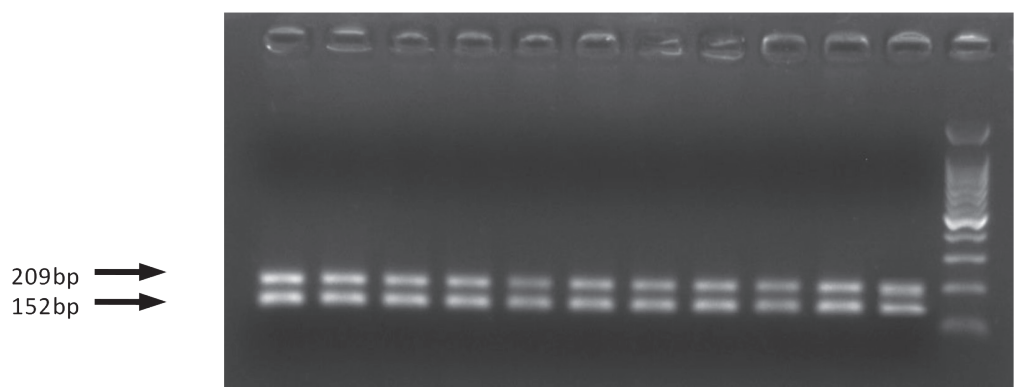

Figure 3. Heterozygous genotypes of the horses misclassified in the passport as solid coloured with white markings

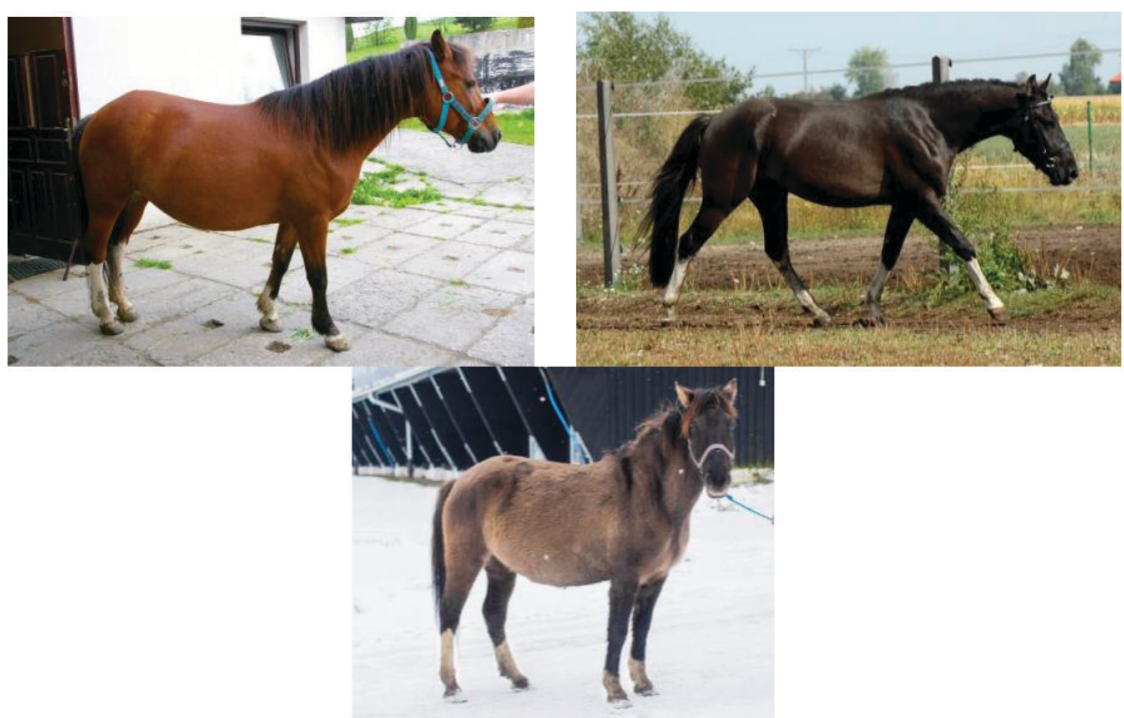

Figure 4. Examples of horses with crypto-tobiano pattern from the group described in the passport as solid coloured with white markings

\section{Discussion}

Coat colour has long been one of the selection criteria for breeding animals, and especially in horses it is described in detail in breed standards. By way of example, black is the preferred colour in Friesian horses, piebald in American Paint horses, and spotted in Appaloosa. By contrast, some colours and patterns are eliminated in other breeds, such as piebald in Connemara ponies (Sponenberg and Bellone, 2017). 
According to the breed standard for Hucul horses, which are a native Polish breed, markings on the limbs and/or the head are not acceptable for breeding (IZ PIB, 2010; PZHK, 2014). In light of the latest research findings (Negro et al., 2017) concerning the genetic determinants of white markings, it appears appropriate to check if the KIT and MITF gene variants described by the authors are equally highly correlated with this trait in Hucul horses. It happens that markings, especially those on the limbs, in fact result from the expression of the gene responsible for piebald colour, which is acceptable in Hucul horses. For someone who describes a horse, it is not possible to discern genotype only on the basis of visible coat colour, which may eliminate a valuable horse in which the piebald pattern manifested itself as minimal. The likelihood of such a mistake is particularly high for the tobiano coat colour, which is characteristic of Hucul horses. Breeders still have a problem in distinguishing the crypto-tobiano pattern from white markings (IZ PIB, 2010; PZHK, 2014; Stachurska and Jansen, 2015).

\section{ECA3 inversion}

The correlation between ECA 3 inversion and the tobiano pattern in different horse breeds was discovered in 2007 by Brooks and her team; they recognized the ECA3 inversion as a direct factor in determining this coat colour in many horse breeds. Our results showed that this relationship also occurs in Hucul horses. All of the examined piebald horses carried the ECA3 inversion and most of them were heterozygotes $(\sim 96 \%)$.

Because the horses from our study were divided into experimental groups mainly based on the passport description, the group of piebald horses included a mare which was qualified as piebald in the passport, although the description stated that none of her parents had this type of coat colour. This mare presented the classic tobiano pattern and was heterozygous, and our study revealed that the mare's dam was misdescribed as solid coloured with white markings, while in fact she was a crypto-tobiano - / inv heterozygote.

An opposite case of misdescribed coat colour was reported by Haase et al. (2008), who identified two Tinker horses that had no inversion and were registered as tobiano. Their phenotypic description showed that they had white markings on the limbs and white belly spots, but they lacked the white spots vertically crossing the body typical for the tobiano pattern.

The most significant results of the present study were obtained for the group of solid coloured horses with white markings, in which the frequency of - / inv heterozygotes and inv / inv homozygotes did not match the expected frequency. Eleven horses out of $61(18 \%)$ carried the ECA3 inversion, which means that almost onefifth of the animals in this group were misdescribed. Similarly to the case of piebald horses, the - / inv genotype was found in one of the solid coloured horses with white markings, which had no tobiano parent. DNA analysis of this horse's dam, which was described as solid coloured with white markings, showed the presence of the inversion. The coat colour of all the horses with the inversion in this group was misclassified when the passport description was made. These 11 horses included 5 mares, 2 stallions, and 4 geldings. In the case of one of the stallions, the space 
for licence number had the comment "not eligible for entry", perhaps as a result of misdescribed coat colour. Among geldings, this mistake could have been the main reason why they were not approved for breeding and castrated.

Horses with misdescribed coat colour in the passports had white markings on all the limbs, and some of them also had small white marks on the body, some of which were not described in the passports. This type of pattern corresponds to crypto-tobiano, which had been reported by Stachurska and Jansen (2015). They analysed the coat colour of offspring, the coat pattern and the origin of 7 Hucul horses with phenotypes similar to those of the misdescribed horses examined in our study. The horses investigated by the mentioned authors were in fact - / inv heterozygotes, and each of them possessed white markings on three or four limbs. One of the horses had a star on the forehead, and 4 horses had blurred patches on the neck or body.

Haase et al. (2008) observed the inversion in 202 examined horses of 4 breeds, the coat colour of which was registered as tobiano. In our study, the result of the examined Huculs was the same and in the group of solid coloured horses none of the 75 horses had the ECA3 inversion. This concerned also subgroup 1, in which the horses had one piebald parent but did not show the tobiano pattern. Our findings can be compared to those of Brooks et al. (2007), Chalupová and Knoll (2008) and Haase et al. (2008), where in the group of solid coloured horses of different breeds, no genotype indicative of the inversion was observed.

It should be highlighted that in our study, almost all the horses that were misdescribed in the passports as solid coloured with white markings possessed white markings on the limbs but not on the head. This agrees with the observations by Sponenberg and Bellone (2017), who noted that this is typical for the minimal tobiano pattern. If the white patches on the limbs were markings not resulting from the presence of the tobiano gene, these horses would probably also have big white markings on the head. This may provide additional guidance, which will facilitate distinguishing the discussed coat colour characteristics when making passport description for a horse. Therefore, when describing Huculs, in which the crypto-tobiano pattern occurs frequently, it is necessary to pay special attention to horses with piebald ancestors. The most reliable way for correct classification of coat colour is to analyse DNA, which will conclusively confirm the presence of the tobiano gene. The PCR test for ECA3 inversion should be used in questionable cases to prevent further loss of valuable horses.

\section{Conclusions}

Summarizing the results, it can be stated that the piebald pattern found in the studied population of Hucul horses is the tobiano pattern, the expression of which is directly determined by the presence of the ECA3 inversion. The numerous mistakes in the coat colour descriptions found in the horse passports point to a significant breeding problem, namely how to distinguish white markings from the crypto-tobiano pattern in Hucul horses. Taking into account that there were $6.3 \%$ of solid coloured horses with white markings, derived from the mating of piebald horses, it is relevant to consider how many of these horses had white markings, and how many were in fact crypto-tobiano. Doubts are even more pertinent in the face of the 
present results, according to which in as much as $52.4 \%$ of the studied horses with minimal tobiano coat colour, the tobiano pattern was wrongly classified as white markings. The continuation of this procedure may result in an increased effect of losing potentially valuable horses for breeding. The results obtained in this research demonstrated the need for verifying the DNA of horses with doubtful coat colour in order to prevent this mistake. In this situation, it appears appropriate to perform further studies aimed at determining factors that control the extent of white patches in piebald Huculs and in solid coloured ones with white markings. It would be interesting to check the correlation in Hucul horses between KIT and MITF gene variants and the white markings mentioned before by the cited authors. The answer could facilitate selection in accordance with the current breed standard.

\section{References}

American Paint Horse Association (APHA) (2007). Guide to Coat Color Genetics: 1.

B a i l e y E., B r o o k s S.A. (2010). Method for screening for a Tobiano coat color genotype. Veterinary Science Faculty Patents, 1: 1-30.

B ro o k s S.A., B e 11 o n e R.R. (2013). Coat color genomics. In: Equine Genomics, Chowdhary B.P. (ed.). New Delhi, India, pp. 143-151.

B ro o k s S.A., Te r ry R.B., B a i l e y E. (2002). A PCR-RFLP for KIT associated with tobiano spotting pattern in horses. Anim. Genet., 33: 301-303.

B rook s S.A., L e a r T., A d e ls o n D., B a i l e y E. (2007). A chromosome inversion near the KIT gene and the Tobiano spotting pattern in horses. Cytogenet. Genome Res., 119: 225-230.

Chalupová P., Knoll A. (2008). KIT gene polymorphism in association with horse coat colour tobiano. Proc. International Ph.D. Students Conference MendelNet 08Agro, Mendel University of Agriculture and Forestry, Ostrava, Czech Republic, 26.11.2008, p. 719.

G i b ał a M. (2012). Dokąd galopuje koń huculski...(in Polish). Hodowca i Jeździec, X, 2: 33.

Giuffra E., Evans G., Tornsten A., Wales R., D a y A., L o oft H., P las tow G., A nders s o n L. (1999). The belt mutation in pigs is an allele at the Dominant White (I/KIT) locus. Mamm. Genome, 10: 1132-1136.

H a a s e B., Ju d e R., B r o o ks S.A., L e e b T. (2008). An equine chromosome 3 inversion is associated with the tobiano spotting pattern in German horse breeds. Anim. Genet., 39: 306-309.

Ha a e B., Brooks S.A., Tozaki T., Burger D., P oncet P.A., Ri eder S., H a s e g a wa T., P e n e d o C., L e e b T. (2009). Seven novel KIT mutations in horses with white coat colour phenotypes. Anim. Genet., 40: 623-629.

Hauswirth R., Jude R., Ha a e B., B ellone R.R., Archer S., Holl H., Brooks S.A., Tozaki T., P en ed o M.C., Ri eder S., L e e b T. (2013). Novel variants in the KIT and PAX3 genes in horses with white-spotted coat colour phenotypes. Anim. Genet., 44: 763-765.

IZ PIB (2010). Program ochrony zasobów genetycznych koni rasy huculskiej (in Polish). Zarządzenie $\mathrm{Nr} 19 / 10$ z dn. 16.04.2010 r., zał. nr 1.

J a n s e n C., J a n s e n P.J. (2012). Czy srokate można jeszcze uratować!? (in Polish). http://www.clubhucul.at/Arge/kultur-tradition/7 piebalds.pdf: 1-21.

Na gl e D.L., K o za k C.A., M a n o H., C ha p man V.M., B u c a n M. (1995). Physical mapping of the Tec and Gabrb1 loci reveals that the Wsh mutation on mouse chromosome 5 is associated with an inversion. Hum. Mol. Genet., 4: 2073-2079.

Negro S., Imsland F., Valera M., Molina A., Solé M., Andersson L. (2017). Association analysis of KIT, MITF, and PAX3 variants with white markings in Spanish horses. Anim. Genet., 48: 349-352.

Polski Związek Hodowców Koni (PZHK) (2014). Program hodowli koni rasy huculskiej (in Polish). Warszawa, pp. 3-18.

R e e s J.L. (2003). Genetics of hair and skin color. Annu. Rev. Genet., 37: 67-90. 
S p on en berg D.P., B e 11 o n e R.R. (2017). Equine Color Genetics (4th ed). IA: Wiley-Blackwell, pp. $171,173-180$.

S t a ch ursk a A. (2012). Odmiany a srokatość (in Polish). Koń Polski, 3: 22-26.

St a churska A., Jansen P. (2015). Crypto-tobiano horses in Hucul breed. Czech J. Anim. Sci., 60: $1-9$.

Stachurska A., Brodacki A., Grabowska J. (2012). Allele frequency in loci which control coat colours in Hucul horse population. Czech J. Anim. Sci., 57: 178-186.

Stephenson D.A., Lee K.H., Nagle D.L., Yen C.H., Morrow A., Miller D., Chap$\mathrm{m}$ a n V.M., B u ć a n M. (1994). Mouse rump-white mutation associated with an inversion of chromosome 5. Mamm. Genome, 5: 342-348.

Received: 16 XI 2018

Accepted: 16 V 2019 